\title{
Determining the accuracy of colorimetric pH testing compared to potentiometric methods
}

\author{
Derek Allan ${ }^{1}$, Helen Heacock ${ }^{2}$
}

1. Lead Author, B. Tech Student, School of Health Sciences, British Columbia Institute of Technology, 3700 Willingdon Ave. Burnaby, BC V5G 3H2

2. Supervisor, School of Health Sciences, British Columbia Institute of Technology, 3700 Willingdon Ave. Burnaby, BC V5G 3H2

\begin{abstract}
Background: Bacterial growth in foods can be prevented by applying various controls to the food product, including adjusting the acidity of the food. Research has indicated that a $\mathrm{pH}$ level of 4.6 or lower will be effective to prevent most bacterial growth. In order to verify this level has been achieved $\mathrm{pH}$ test strips (colorimetric) or a digital calibrated $\mathrm{pH}$ meter (potentiometric) can be used. This study attempted to quantify the degree of accuracy that $\mathrm{pH}$ test strips have compared to the calibrated $\mathrm{pH}$ meter.

Method: MColorpHast ${ }^{\mathrm{TM}} \mathrm{pH}$ indicator strips with a $\mathrm{pH}$ range of 0-14 were tested against a calibrated Extech pH100 meter. In this study 40 samples of rice were acidified to varying levels. Each sample was measured with both colorimetric and potentiometric method. Results were compared to determine the level of accuracy of the $\mathrm{pH}$ test strips. As well, test strips were used to measure $\mathrm{pH}$ in a variety of different coloured preserves.

Results: A two-tailed test showed that there was a statistically significant difference between the readings from the $\mathrm{pH}$ test strips and the digital $\mathrm{pH}$ meter $(\mathrm{P}=0.0003)$.

Conclusion: Based on the results, it can be concluded that both methods of measurement are not equally accurate. A calibrated $\mathrm{pH}$ meter will give more accurate readings of $\mathrm{pH}$ levels and should be used in most cases to confirm food safety with a high degree of confidence. In testing dark coloured jellies and preserves, $\mathrm{pH}$ test strips should not be relied on as they will be stained by the food, making the colorimetric reading difficult to determine accurately.
\end{abstract}

Keywords: $p H$, test strips, calibrated $\mathrm{pH}$ meter, food safety, acidity, accuracy, colorimetric, potentiometric, comparison.

\section{INTRODUCTION}

Food of all varieties may provide a medium for the growth of unwanted pathogens that can cause illness to a consumer. There are a number of ways food can become contaminated, beginning at its harvest all the way through to when it is served and consumed. To prevent contamination of the food, a variety of controls can be applied that will inhibit pathogenic growth and reduce the risk of a foodborne illness. Factors that influence the growth of harmful microorganisms include the nutrient availability of the food, the temperature and length of time for which the pathogens are allowed to grow, the acidity of the food, the presence of oxygen, and the water activity or moisture content of the food (1). All of these factors can be used simultaneously to prevent growth. The more controls in place, the greater the prevention against microbial growth. Using multiple factors for preventing pathogen growth is known as the "hurdle concept"; the more 
controls in place, the more barriers the bacteria will have to overcome for growth (2). While it is important to consider all factors that impact levels of contamination on food, the level of acidity as a control for microbial growth will be the focus of this study.

Acidity and alkalinity is measured on a $\mathrm{pH}$ scale that ranges from 0 to 14 , with a $\mathrm{pH}$ of 0 being the most acidic, a $\mathrm{pH}$ of 7 being neutral, and a $\mathrm{pH}$ of 14 being the most alkaline.

Microorganisms require a specific $\mathrm{pH}$ range for optimal growth; they will not grow outside of that $\mathrm{pH}$ range (2). When the $\mathrm{pH}$ range of the food is controlled, we can selectively inhibit pathogenic growth by selecting the range at which bacteria do not readily grow. The majority of pathogens grow best at a neutral $\mathrm{pH}$ of around 7 (2). When the $\mathrm{pH}$ drops below 4 the majority of pathogenic growth is inhibited (2). Therefore having a higher acidity can effectively prevent pathogen proliferation. Some foods have a naturally high acidity which will help protect them from contamination. Meat and fish for example tend to have a more neutral $\mathrm{pH}$ which makes them susceptible to pathogens (2).

To ensure that proper $\mathrm{pH}$ levels are being met, measurements can be taken with $\mathrm{pH}$ litmus paper strips or a calibrated potentiometric $\mathrm{pH}$ meter. The purpose of this research was to determine whether $\mathrm{pH}$ test strips can be depended on for giving accurate $\mathrm{pH}$ readings.

\section{EVIDENCE REVIEW}

Foods may be classified as either high or low acid foods. High acid foods have a $\mathrm{pH}$ of 4.6 or lower, whereas low acid foods have a $\mathrm{pH}$ greater than 4.6. A pH level of 4.6 is often referred to because this is the point at which growth of Clostridium botulinum is effectively inhibited (2). When canning foods, $\mathrm{pH}$ is commonly used as a control. C. botulinum is a major concern for contamination and growth in canned goods, which is why its $\mathrm{pH}$ range for growth is often relied upon. If the food has a
pH greater than 4.6, other control factors such as temperature control should also be implemented for prevention of bacterial growth.

In the processing of foods $\mathrm{pH}$ can be controlled with the addition of $\mathrm{pH}$ adjusting agents. In Division 15, Part B of the federal Food and Drug regulation Table 10 outlines the wide variety of food additives that may be used as $\mathrm{pH}$ adjusters (3). Foods that are commonly controlled by lowering the $\mathrm{pH}$ are known as acidified or pickled foods. Acidified foods are those that have initially low-acid to which acids or acidic foods are added to lower the $\mathrm{pH}$ and control bacterial growth (4). Foods that are commonly acidified include pickled beets, red bell peppers, pears, some tropical fruits that are naturally less acidic, green olives, tomato salsa, or foods that are being canned into a hermetically sealed container (4). In hermetically sealed containers $C$. botulinum is of particular concern as they are a spore forming bacteria that vegetate in the absence of oxygen.

Another example in which acidity is increased in a food to help curb pathogenic growth is in the preparation of sushi rice. Rice is particularly susceptible to the microorganism Bacillus cereus which is a spore forming organism that can vegetate after being cooked at high temperatures, creating a risk for foodborne illnesses. Sushi rice is traditionally held at room temperature so the addition of vinegar, which has a low $\mathrm{pH}$, is used to lower the overall $\mathrm{pH}$ of the rice and establish a control for pathogenic growth since temperature is not being used as the control (5). It has been found that a $\mathrm{pH}$ of around 5.0 will sufficiently prevent the growth of B. cereus (6). As part of the processing of these foods it is imperative that the processing facilities, service establishments, and those performing food safety inspections verify that appropriate $\mathrm{pH}$ levels are being met with reliable $\mathrm{pH}$ measuring equipment. 
Other health factors to consider with regards to pH levels

With regards to the acidity and alkalinity of foods there are other health concerns to be aware of when acidifying foods. When dealing with acidic foods such as fruit juice, maple syrup or tomatoes, it is important not to store these items in metal containers for extended periods of time. The acid in these foods can dissolve the metal container they are being held in and could lead to potential metal food poisoning (7). A food processor or handler should be aware of the $\mathrm{pH}$ levels of the foods they are dealing with so they can choose appropriate containers and avoid metal poisoning.

Other health concerns around acidic foods include the potential for dental erosion with a highly acidic diet (8). Whether a more acidic or alkaline diet is better for your overall health has yet to be determined. Some studies have shown that having a more alkaline diet may reduce morbidity and mortality from chronic diseases, however more research is needed in this area (9).

\section{Measuring the $\mathrm{pH}$ : potentiometric vs.} colorimetric

Potentiometric measurement of acidity involves using an electric calibrated $\mathrm{pH}$ meter that consists of an electrode probe and a digital display. Colorimetric measurement involves the use of dyed paper that changes colour depending on the $\mathrm{pH}$ level. To accurately measure the $\mathrm{pH}$ of food by either method requires preparation of a uniform sample where any excess oils are removed or decanted from the food (10). For solid foods, a blender should be used to make a slurry by adding $50 \mathrm{ml}$ of distilled water for every 100 grams of food. Once finished blending, a pH measurement can be taken by either dipping the electrode of the calibrated $\mathrm{pH}$ meter or the paper test strip into the slurry (10). It is also important to maintain a consistent temperature while measuring $\mathrm{pH}$ levels, as the
$\mathrm{pH}$ values will fluctuate with temperature. When measuring strongly acidic items the $\mathrm{pH}$ level (3 or lower) will not fluctuate with temperature, however neutral and alkaline foods will have a $\mathrm{pH}$ level that is temperature dependant (11). When calibrating the $\mathrm{pH}$ meter a consistent temperature should be maintained.

Using colorimetric measurement with paper $\mathrm{pH}$ strips can be an inexpensive and a quick way to roughly determine the acidity of a food. They are stable and generally do not have explicit expiration dates. To maintain their working condition they should not be stored in direct sunlight or humid areas (12). Paper strips indicate the $\mathrm{pH}$ level by changing colour. They come with a colour scale that helps the user determine the $\mathrm{pH}$ range by matching the colour of the strip. Papers can be purchased in rolls or strips and may indicate wide or narrow $\mathrm{pH}$ ranges (13). The most sensitive $\mathrm{pH}$ test strips that are available can indicate differences of up to $0.2 \mathrm{pH}$ units (13).

With potentiometric methods, the $\mathrm{pH}$ meter must first be calibrated. To do so, two standard buffer solutions must be used and should be at the same temperature (13). After rinsing the electrode with deionized water and drying it, it can be submerged into the first standard buffer, then the meter should be adjusted so that it matches that of the $\mathrm{pH}$ of the buffer. It should be placed into the same buffer twice more to ensure the successive readings are also accurate. Repeat this procedure with a second standard buffer of a different $\mathrm{pH}$ to complete the calibration; this is known as two point calibration (13). It is recommended to use a pH meter that has an accuracy within 0.02 units (10).

\section{Guidelines for acidification and $p H$} measurement

In the province of British Columbia there are no specific regulations that require monitoring and maintaining certain $\mathrm{pH}$ levels in specified foods. There are several guidelines 
that recommend $\mathrm{pH}$ levels should be below 4.6, particularly for foods that are commonly prepared at home for sale at markets such as jellies, jams, pickled vegetables, and salsas (14).

The British Columbia Centre for Disease Control (BCCDC) also has specific recommendations for $\mathrm{pH}$ levels in sushi rice that is cooked then kept at room temperature (15). At these temperatures rice is at greater risk for pathogenic growth and as such vinegar must be added to lower the $\mathrm{pH}$ and put in place another barrier to bacterial proliferation. The BCCDC recommends acidifying the room temperature sushi rice to a $\mathrm{pH}$ of 4.2 to ensure pathogenic growth is inhibited (15).

The Manual of Procedures for Meat Hygiene issued by the government also gives recommendations for those involved in food processing and inspection (16). It is recommended that paper $\mathrm{pH}$ strips be used for checking foods while they are being processed, or when finished. The only time it is not recommended to use $\mathrm{pH}$ strips is when the $\mathrm{pH}$ is 4.0 or higher (16). At this point the accuracy of the paper $\mathrm{pH}$ strips cannot be relied upon to guarantee the product has a $\mathrm{pH}$ less than 4.6. Verifying their accuracy in this study will determine whether or not this is an appropriate recommendation.

\section{Other applications of $p H$ control}

When canning foods, verifying a proper $\mathrm{pH}$ has been met is an important control point to stop pathogenic growth, especially for preventing $C$. botulinum. The quality of the food such as flavour, colour, and texture can also be impacted by $\mathrm{pH}$ levels, so monitoring levels will be of value to the food processor (17). Testing the $\mathrm{pH}$ of a food is a useful quality control check not only for prevention of microbe growth but also for maintaining desired flavour. This gives food processors multiple reasons to ensure proper acidity is being met.

\section{$\underline{\text { Strengths and limitations }}$}

In the research around $\mathrm{pH}$ as a food safety control, it has been well established that $\mathrm{pH}$ is effective for prevention of bacterial growth. Sufficient evidence has shown that lowering $\mathrm{pH}$ is an effective food safety control. As a result specific $\mathrm{pH}$ limits have been determined for various food pathogens. For example, maintaining a $\mathrm{pH}$ below 4.6 will effectively control most bacterial growth. It is generally known that calibrated $\mathrm{pH}$ meters will provide more accurate readings compared to paper test strip. However there is little research that has quantified how accurate or inaccurate paper strips are.

\section{Gaps in the research and knowledge}

To date there is little research with regards to comparing the accuracy of $\mathrm{pH}$ test strips to that of a calibrated $\mathrm{pH}$ meter. One study looked at comparing the accuracy of four different portable $\mathrm{pH}$ meters compared to $\mathrm{pH}$ paper for measuring the acidity of dog urine. The study found that the calibrated $\mathrm{pH}$ meters provided near perfect accuracy, whereas the paper strips had poor to moderate accuracy (18). With regards to testing the $\mathrm{pH}$ of foods there is insufficient literature to conclude whether or not $\mathrm{pH}$ strips provide sufficiently accurate measurement to confer absolute food safety. As they are the less expensive method of measurement, knowing whether they can be relied on is important as they are more easy to use for the general population and food establishments.

\section{METHODS}

This experiment involved using 40 different samples of cooked rice that had been made into a slurry, with each sample measuring exactly $50 \mathrm{~mL}$. Regular white rice was cooked in a rice cooker, then blended into a uniform slurry with a handheld blender. Distilled water was added to the slurry to aid with the blending 
without impacting the $\mathrm{pH} ; 50 \mathrm{~mL}$ of water can be used for every $100 \mathrm{~mL}$ of food without impacting the $\mathrm{pH}$ value (3). The slurry was then separated into 40 different beakers. Each beaker contained $50 \mathrm{~mL}$ of rice. Each rice sample was acidified independently with different amounts of white vinegar to create varying levels of $\mathrm{pH}$ across all of the samples. A Pasteur pipette was used to add the white vinegar to the rice sample, starting with $0.5 \mathrm{~mL}$ of vinegar for the first sample. Increments of $0.5 \mathrm{~mL}$ of white vinegar were added to subsequent samples. This resulted in the $40^{\text {th }}$ sample receiving $15.0 \mathrm{~mL}$ of white vinegar. All ingredients were kept at room temperature prior to mixing to ensure each sample is the same temperature, and prevent fluctuations in $\mathrm{pH}$ readings that can result from temperature differences (11). A digital food grade thermometer was used to ensure each sample was the same temperature. The $\mathrm{pH}$ of the samples were first read using the calibrated $\mathrm{pH}$ meter, and then again with the $\mathrm{pH}$ paper strips. The $\mathrm{pH}$ meter was calibrated using two buffer solutions, one with a $\mathrm{pH}$ of 4.0 and the other with a $\mathrm{pH}$ of 7.0.

To further verify the accuracy of $\mathrm{pH}$ test strips across different food products, a variety of jarred preserves were tested. The specific purpose was to determine whether coloured food items can stain the test strip to the point where the ability to accurately read the strip has been compromised.

The null hypothesis for this study is that readings obtained from $\mathrm{pH}$ test strips are equally as accurate as the readings obtained from a calibrated $\mathrm{pH}$ meter. The alternative hypothesis is that readings obtained from the $\mathrm{pH}$ test strips are either higher or lower than the readings from a calibrated $\mathrm{pH}$ meter.

\section{RESULTS}

The data produced from conducting this experiment is entirely numerical. Both the calibrated $\mathrm{pH}$ meter and the $\mathrm{pH}$ test strips produce numbers from the $\mathrm{pH}$ scale which ranges from 0 to 14 . The mean $\mathrm{pH}$ reading from the calibrated $\mathrm{pH}$ meter was compared to the mean $\mathrm{pH}$ reading from the $\mathrm{pH}$ test strips. The standard deviation helps to elucidate how the data is spread around the mean. The data from this experiment was analyzed using NCSS 11 (19). As the data compares the means from two independent groups an Independent t-test was used for analysis. The descriptive statistics from the experiment are shown in Figure 1 (below).

\begin{tabular}{|l|c|c|c|c|}
\hline $\begin{array}{l}\text { pH } \\
\text { Measure }\end{array}$ & Count & Mean & Median & $\begin{array}{c}\text { Standard } \\
\text { Deviation }\end{array}$ \\
\hline Meter & 40 & 3.22 & 3.2 & 0.26 \\
\hline Strip & 40 & 3.07 & 3 & 0.35 \\
\hline
\end{tabular}

Figure 1: A table outlining the descriptive statistics from the study.

At the time of the experiment, the laboratory in which the study was conducted held a stable temperature of $20^{\circ} \mathrm{C}$ throughout the duration of the study. The data was successfully collected from all 41 samples using both the $\mathrm{pH}$ test strips and the $\mathrm{pH}$ meter. Looking at the Test of Assumptions, the Kurtosis Normality shows that normality was rejected. Therefore this must be analyzed using non-parametric test results from the Mann Whitney U test. The two-tailed test was examined because it is unclear whether the $\mathrm{pH}$ readings from the test strips would be higher or lower than that of the $\mathrm{pH}$ meter. A Pvalue of 0.0003 was achieved from the statistical analysis. Therefore the null hypothesis is rejected, and it can be concluded that there is a statistically significant difference in $\mathrm{pH}$ readings between the $\mathrm{pH}$ strips and the $\mathrm{pH}$ meter. This signifies that both methods of measurement are not equally accurate and $\mathrm{pH}$ test strips cannot be relied upon as confidently as a $\mathrm{pH}$ meter for confirming safety in foods that use acidity as a control for pathogen growth.

There is strong practical significance from this result as it confirms the accuracy of $\mathrm{pH}$ test strips to be less reliable than the $\mathrm{pH}$ meter. Therefore suggesting the use of $\mathrm{pH}$ meters over $\mathrm{pH}$ strips may be more practical for 
food processors. The weakness from this test is that the power is relatively low at $60 \%$, when it should be $80 \%$ or over to have an acceptable power. In order to improve this result the number of samples to be measured could be increased.

From examining the impact that different coloured preserves have on staining the $\mathrm{pH}$ test strip, another weakness of test strips was uncovered. The test strips that were dipped in the cherry and blackberry preserves were found to be sufficiently stained to make accurately reading the results impossible. Those that were dipped in the lighter pepper jelly and marmalade remained unstained and could still be read accurately.

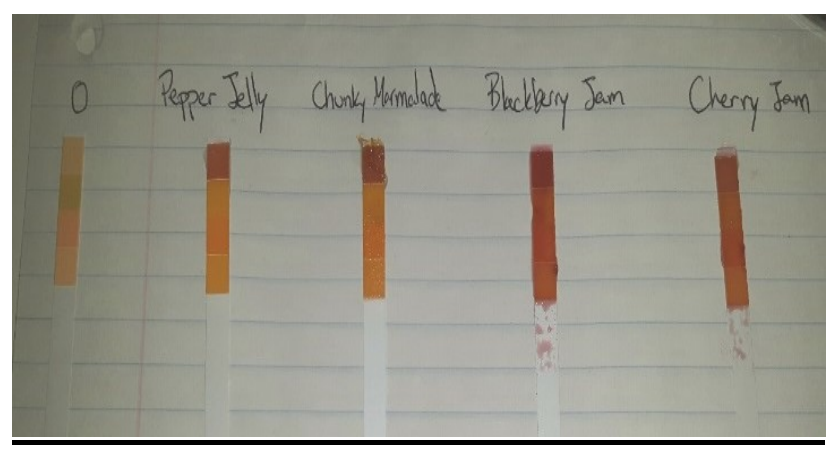

Figure 2: Shows the extent of staining from different coloured preserves.

\section{DISCUSSION}

In comparing the two available methods for measuring acidity of food, using $\mathrm{pH}$ test strips or a calibrated $\mathrm{pH}$ meter, this study found that the $\mathrm{pH}$ meter offers more consistently reliable results. It could not be statistically concluded that $\mathrm{pH}$ test strips deliver as accurate readings as a calibrated $\mathrm{pH}$ meter. Despite this finding, there are still instances in which $\mathrm{pH}$ test strips may be useful to determine a food product's relative safety.

The standardly used $\mathrm{pH}$ level to confirm that pathogenic growth will be inhibited is 4.6. Food products should be below this level in order to be deemed capable of curbing microbiological growth (2). Due to the nature of the measuring process using $\mathrm{pH}$ test strips, one can only determine the $\mathrm{pH}$ range that the food product falls within. Test strips cannot determine the $\mathrm{pH}$ level down to a specific decimal point, whereas the $\mathrm{pH}$ meter is able to do this. Therefore the $\mathrm{pH}$ test strips should only be relied upon to confirm a $\mathrm{pH}$ range. $\mathrm{A} \mathrm{pH}$ meter should be used in place of test strips when confirming that the level is a below a specific point such as 4.6. This practice is confirmed by the standard operating procedure recommended in The Manual of Procedures for Meat Hygiene issued by the federal government. The manual recommends $\mathrm{pH}$ strips be used for checking foods while they are being processed, or when finished. The only time it is not recommended to use $\mathrm{pH}$ strips is when the $\mathrm{pH}$ is 4.0 or higher (15).

This study looked at an additional component of the colorimetric method, to determine if coloured foods would impact the ability to accurately read the test strip. It was found that lighter coloured foods such as rice slurry and light preserves did not impede the ability to read the strips whereas dark jams stained the strip such that it could not be read accurately. The British Columbia Guideline for the Sale of Foods at Temporary Markets recommends that products such as salsa, jams, and jellies should have a $\mathrm{pH}$ of 4.6 or lower (14). Due to the discoloration impact that some of these products have on $\mathrm{pH}$ test strips, this study supports using a $\mathrm{pH}$ meter as opposed to test strips for verifying the $\mathrm{pH}$ of dark coloured products.

There is little research that determines the accuracy level of $\mathrm{pH}$ strips, however the findings from this experiment do align with another study that compared $\mathrm{pH}$ meters to test strips for measuring the acidity of dog urine. That study found that the calibrated $\mathrm{pH}$ meters provided near perfect accuracy, whereas the paper strips had poor to moderate accuracy (17). With regards to testing the $\mathrm{pH}$ of foods there is 
insufficient literature to conclude whether or not $\mathrm{pH}$ strips provide sufficiently accurate measurement to confer absolute food safety. This study aimed to fill that gap in research.

\section{RECOMMENDATIONS}

Due to the relative inaccuracy of $\mathrm{pH}$ test strips compared to using a calibrated $\mathrm{pH}$ meter for measuring acidity levels, it is recommended that $\mathrm{pH}$ test strips only be used in certain cases. In order to confirm the final $\mathrm{pH}$ of a prepared food product, a calibrated $\mathrm{pH}$ meter should be used as it will give a more accurate reading down to several decimal points. The $\mathrm{pH}$ test strips may be used more as an indicator that the acidity of food falls within a specific desired range. This could be used to confirm the general $\mathrm{pH}$ range of a food product while it is being prepared, which will help the producer determine whether adjustments to the acidity need to be made.

Due to the staining of the $\mathrm{pH}$ test strips that result from being dipped in dark jams and jellies, they cannot be relied on for accurate readings with these products. To test the $\mathrm{pH}$ of a dark coloured and staining food product, only a calibrated $\mathrm{pH}$ meter should be used.

\section{LIMITATIONS}

In the execution of this study there were factors that could be improved upon to increase the validity of the results. For measuring the $\mathrm{pH}$ of the prepared rice slurry, $\mathrm{pH}$ test strips that measure the full range of the $\mathrm{pH}$ scale were used. Test strips with narrower $\mathrm{pH}$ ranges do exist, and are able to measure the level of $\mathrm{pH}$ to a more specific degree. There is potential that these strips would provide more accuracy than the ones used in this study, however the lab was unable to provide the narrow ranged strips.
Another limitation in this study is the lack of research around this topic. In order to definitively determine whether $\mathrm{pH}$ strips should be used as a reliable method of measuring $\mathrm{pH}$, more research is needed.

\section{FUTURE RESEARCH}

1. The $\mathrm{pH}$ of the rice slurry was observed to increase slightly over time. Perhaps more time is needed for the $\mathrm{pH}$ to settle, as it seemed to become less acidic over time. A study could determine the length of time needed for the $\mathrm{pH}$ level to stabilize

2. Compare a variety of different strips, using different brands and $\mathrm{pH}$ ranges, to determine whether some are better than others.

3. Another study could determine if there a way to measure darkly coloured preserves without staining the test strip beyond the ability to read it accurately.

\section{CONCLUSION}

It has been well established that monitoring $\mathrm{pH}$ levels for various foods is used as an important control for pathogenic growth. To date, few studies have quantified the level of accuracy that paper $\mathrm{pH}$ strips can produce. Food safety guidelines recommend only using $\mathrm{pH}$ strips in certain circumstances because of unknown or unreliable accuracy. This study has determined that the calibrated $\mathrm{pH}$ meter will offer more accurate and therefore reliable results than a $\mathrm{pH}$ test strip. The findings from this study support the reasoning behind only using $\mathrm{pH}$ test strips as a rough indication of the $\mathrm{pH}$ level of a certain food product, and not to try and determine the exact $\mathrm{pH}$ level of the product with the strips. The $\mathrm{pH}$ test strips are better for quick measurements to verify it is within a certain desired range, but if one wants to look at finer measurements of $\mathrm{pH}$ levels they should not be 
relied upon. A pH meter would be more suitable in this case.

The $\mathrm{pH}$ test strips may also be unreliable when testing certain food products that may stain the strip, making the colorimetric results difficult to read. For these cases, measuring foods such as dark jams and salsa, it should be noted that a $\mathrm{pH}$ meter will be more reliable. The $\mathrm{pH}$ was found to have risen after the vinegar sat in the rice for extended periods of time. More research can be done in this area to determine how much time is needed for the $\mathrm{pH}$ to reach a stable level. Food operators should be aware that $\mathrm{pH}$ levels may increase shortly after adding vinegar to the rice, therefore more stringent monitoring procedures may be necessary.

\section{ACKNOWLEDGMENTS}

This research project was supported by the British Columbia Institute of Technology and the program for Environmental Health.

\section{COMPETING INTEREST}

The authors declare that they have no competing interests.

\section{REFERENCES}

1. Forsythe S. The Microbiology of Safe Food. Oxford: Blackwell Science; 2011.

2. Wareing P, Stuart F, Fernandes R. Microfacts. Surrey: Leatherhead Pub.; 2010.

3. Government of Canada. Marketing Authorization for Food Additives That May Be Used as pH Adjusting Agents, AcidReacting Materials or Water Correcting Agents. Ottawa: Food and Drugs Regulation; 2012.

4. Felix H. Barron, Angela M. Fraser. Acidified Foods: Food Safety
Considerations for Food Processors. Clemson, SC: INTECH Open Access Publisher; 2013.

5. Lee C., Heacock H. Safety and $\mathrm{pH}$ Measurements of Sushi Rice in Japanese Restaurants in Burnaby BC, Canada [Internet]. Burnaby, BC: British Columbia Institute of Technology; 2014. Available from:

$\underline{\text { http://www.ccnse.ca/sites/default/files/BCIT }}$ -Lee-2014.pdf

6. Valero M, Fernández P, Salmerón M. Influence of $\mathrm{pH}$ and temperature on growth of Bacillus cereus in vegetable substrates. International Journal of Food Microbiology. 2003; 82(1):71-79.

7. Government of Ontario. Food Safety: A Guide for Ontario's Foodhandlers. WindsorEssex: Queen's Printer for Ontario; 2013.

8. Sirimaharaj V, Messer L, Morgan M. Acidic Diet and Dental Erosion among Athletes. Australian Dental Journal. 2002; 47(3):228236.

9. Schwalfenberg G. The Alkaline Diet: Is There Evidence That an Alkaline pH Diet Benefits Health? Journal of Environmental and Public Health. 2012; 2012:1-7.

10. Government of Manitoba. $\mathrm{pH}$ Meter Guide: Food Safety Info. Winnipeg, MB; 2013

11. Barron J, Ashton C, Geary L. Effects of Temperature on $\mathrm{pH}$ Measurement. County Clare: Reagecon Ltd.; 2006.

12. Ingham B. Purchasing and Using a $\mathrm{pH}$ Meter. Wisconsin: University of Wisconsin; 2009.

13. Food Chemicals Codex. $5^{\text {th }}$ ed. Washington, D.C.: National Academy Press; 2003.

14. Guidelines for the Sale of Foods at Temporary Food Markets. Vancvouer: Vancouver Coastal Health, BCCDC; 2014. 
15. Sushi Safety. Vancouver: British Columbia Centre for Disease Control; 2017 [7 January 2017]. Available from:

http://www.bccdc.ca/resourcegallery/Documents/Educational\%20Material s/EH/FPS/Fish/SushiSafety.pdf

16. Meat hygiene manual of procedures. Ottawa: Canadian Food Inspection Agency; 2014.

17. Gould W. Total quality assurance for the food industries. $3^{\text {rd }}$ ed. Baltimore, MD: CTI Publications; 2013.

18. Johnson K, Lulich J, Osborne C. Evaluation of the reproducibility and accuracy of $\mathrm{pH}$ determining devices used to measure urine $\mathrm{pH}$ in dogs. Journal of the American Veterinary Medical Association. 2007; 230(3):364-369.

19. NCSS Statistical Software. Kaysville, Utah: NCSS; 2017. 